Voix et Images

voixetimages

\title{
Bibliographie de Michael Delisle
}

\section{Shanna Lee Mumm}

Volume 38, numéro 3 (114), printemps-été 2013

Michael Delisle

URI : https://id.erudit.org/iderudit/1018315ar

DOI : https://doi.org/10.7202/1018315ar

Aller au sommaire du numéro

Éditeur(s)

Université du Québec à Montréal

ISSN

0318-9201 (imprimé)

1705-933X (numérique)

Découvrir la revue

Citer ce document

Mumm, S. L. (2013). Bibliographie de Michael Delisle. Voix et Images, 38(3), 101-108. https://doi.org/10.7202/1018315ar d'utilisation que vous pouvez consulter en ligne.

https://apropos.erudit.org/fr/usagers/politique-dutilisation/ 


\section{B IBLIOGRA PHIE DE MICHAEL DELISLE}

$+++$

SHANNA LEE MUMM

Université de l'Alberta

\section{E U V RES}

A. Poés i e

+ L'agrandissement, Talence, Castor astral/l'Atelier de l'Agneau, coll. «Plaisirs solitaires», 1983, $28 \mathrm{p}$.

+ L'extase neutre, Montréal, Éditions de La Nouvelle Barre du jour, 1985, 44 p. (D’abord paru dans la revue La Nouvelle Barre du jour, no 147.)

+ Mélancolie, Montréal, Éditions de La Nouvelle Barre du jour, coll. «On voit plus de prodiges merveilleux et de belles choses", 1985, 23 p.

+ Les changeurs de signes, Montréal, Éditions de La Nouvelle Barre du jour, 1987, 54 p. (D’abord paru dans la revue La Nouvelle Barre du jour, nº 192.)

+ Fontainebleau, Montréal, Les Herbes rouges, 1987, 129 p.

+ Les mémoires artificielles, Trois-Rivières, Écrits des Forges, coll. «Les rivières», 1987, 64 p.

+ Chose vocale, Montréal, Les Herbes rouges, 1990, 77 p.

+ Long glissement, Montréal, Leméac, coll. «Poésie», 1996, 117 p.

+ Prière à blanc, Montréal, Éditions du Noroît, 2009, 71 p.

\section{B. Romans et recueils de nouvelles}

+ Drame privé, Montréal, Les Herbes rouges, 1989, 115 p. (Réédition: Paris, P.O.L., 1990, 128 p.)

+ Helen avec un secret et autres nouvelles, Montréal, Leméac, coll. "Nouvelles Leméac», 1995, 138 p. (Réédition: Montréal, Bibliothèque québécoise, 2009, 123 p.)

+ Le désarroi du matelot, Montréal, Leméac, coll. «Roman Leméac», 1998, 139 p. (Réédition: Montréal, Bibliothèque québécoise, 2002, 133 p.)

+ Dée, Montréal, Leméac, 2002, 124 p. (Réédition : Montréal, Bibliothèque québécoise, 2007, 129 p.)

+ Le sort de Fille, Montréal, Leméac, 2005, 125 p.

+ Tiroir no 24, Montréal, Boréal, 2010, 129 p.

\section{Livre d'art}

+ Voile: Jacques Perron, avec la collaboration de Nicole Gingras et Jacques Perron, Montréal, Éditions Nicole Gingras, 1998, 55 p. 


\section{Mémoire de maîtrise}

+ Le désarroi du matelot. Passages de la représentation à la présence, mémoire de maîtrise, Montréal, Université du Québec à Montréal, 1992, 136 f.

\section{E. Textes littéraires parus dans des périodiques et des collectifs}

+ «L'importance d'être S. B.», Mœbius, nº 7, 1979, p. 14-16.

+ «Black magic», Hobo-Québec, n 42, 1980, p. 44.

+ "Chimie d'une allure inf.», Hobo-Québec, nº 43, 1980, p. 47.

+ «Dé», La Nouvelle Barre du jour, n 96, 1980, p. 15-21.

+ "Extraits de séquences», Atelier de production littéraire des Forges, n 10, 1980, p. 25-27.

+ "Extraits de La _ _ _ _ _ _ _ _ _ _ filmique (récit en préparation)", Atelier de production littéraire des Forges, nº 13, 1980, p. 44-46.

+ «Format d'un lieu inf.», Mœbius, nos 10-11, 1980, p. 25-26.

+ «Clef», Hobo-Québec, nos 44-45, 1981, p. 2-3.

+ «Il croirait... », Mœbius, no 13, 1981, p. 9-10.

+ «Perditions inexactes», La Nouvelle Barre du jour, nos 100-101, 1981, p. 61-66.

+ «Papier jaune», La Nouvelle Barre du jour, nº 107, 1981, p. 5-10.

+ «Stock», Influx, n 1, 1981, p. 9-14.

+ «Un meurtre trop littéraire», Minuit, n 42, 1981, p. 62-63.

+ « Histoire du roi de Bohême et de ses sept châteaux », Minuit, nº 46, 1981, p. 20-24.

+ «Le terrain de jeu», Hobo-Québec, nos 46-47, 1981, p. 10-11.

+ «Bizarre», Imagine, nº 12, 1982, p. 8-12.

+ «Doublure», Atelier de production littéraire des Forges, nº 16, 1982, p. 29-30.

+ «L'épaule», Influx, n² 2, 1982, p. 30-33.

+ «Gésir», La Nouvelle Barre du jour, no 113, 1982, p. 17-28.

+ «Bel effet», Lèvres urbaines, nº 1, 1983, p. 12.

+ «Le caractère de l'imprimante», La Nouvelle Barre du jour, nos 122-123, 1983, p. 80-84.

+ «L'incipit, les grandes quantités de vin et lui», La Nouvelle Barre du jour, nºs 127-128, 1983, p. 153-160.

+ "Pacifiques d'entrer", Lèvres urbaines, n 2, 1983, p. 13.

+ «L'explication», Lèvres urbaines, n 4, 1983, 20 p.

+ "Récit de retour ", La Nouvelle Barre du jour, n 133, 1983, p. 49-54.

+ «De l'empilement», Atelier de production littéraire des Forges, n 18, 1984, p. 20.

+ « Je lis un lecteur», Influx, n 4, 1984, p. 44-50.

+ "La pluie, le signet et le conférencier», La Nouvelle Barre du jour, n 140, 1984, p. 49-52.

+ «Lecture à vue», Lèvres urbaines, n 9, 1984, p. 7.

+ «Profil laminer (collage)» [avec Claude Beausoleil], La Nouvelle Barre du jour, n 144, 1984, p. 15-37.

+ "L'annoté», Lèvres urbaines, nº 10, 1985, p. 18.

+ «Une autre ville (mise en mémoire)», Lèvres urbaines, no 11, 1985, p. 18.

+ "L'esprit des langues », La Nouvelle Barre du jour, n 149, 1985, p. 7-14.

+ «Cours d'été» [avec Sylvie Tremblay], La Nouvelle Barre du jour, nº 163, 1985, p. 13-16.

+ «Donne-moi un whisky», Imagine, n 32, 1986, p. 11-32.

+ «Intentions. Isfjorden-Smola et Ranger. Deux versions de la blancheur» [avec Rober Racine], $\mathrm{La}$ Nouvelle Barre du jour, nos 189-190, 1986, [s. p.]. 
+ «Les mémoires artificielles», Urgences, n 15, 1986, p. 12.

+ «Faire mention», Lèvres urbaines, n 15, 1987, 24 p.

+ «Octobre: Rock Garden» [avec Claude Beausoleil], Urgences, n 16, 1987, p. 12-13.

+ «Stadt», Collectif, L'art québécois en mutation 1944-1956, Trois-Rivières, Écrits des Forges, 1987, p. [17].

+ "L'émotion de l'autre (extraits)», Estuaire, n 50, 1988, p. 36.

+ «D'immenses coloriages», Poetics Journal, nº 8, 1989, p. 108.

+ «L'émotion de l'autre», Trois. Revue d'écriture et d'érudition, vol. IV, nº 3, 1989, p. 83-85.

+ «Mon frère en tête», Estuaire, nº 52, 1989, p. 27-30.

+ «Extase neutre», La Nouvelle Barre du jour, nos 223-224-225, 1990, p. 461-462.

+ «Les changeurs de signes», La Nouvelle Barre du jour, nºs 223-224-225, 1990, p. 579-580.

+ «Terre en friche», Recueil, n 21, 1992, p. 70-89.

+ «La conscience», Estuaire, n 72, 1994, p. 19-20.

+ «Stylet», Estuaire, no 72, 1994, p. 21-22.

+ «Vierge exquis», Estuaire, no 93, 1998, p. 91.

+ «Mil neuf cent quatre-vingt-dix-neuf», Estuaire, no 98, 1999, p. 60.

+ «Le pont», collectif, Montréal, la marge au cœur, Paris, Éditions Autrement, coll. «Littératures. Romans d'une ville», 2004, p. 95-116.

+ «Sept poèmes différents», Exit, n 39, 2005, p. 53-60.

+ "L'arrêt», XYZ. La revue de la nouvelle, n 102, été 2010, p. 7-10.

\section{F. Avant-propos, textes d'opinion et communications}

+ «Liminaire», Lèvres urbaines, nº 2, 1983, p. 3.

+ "Cette liste aurait cent lignes», Les cent lignes de notre américanité. Actes du colloque tenu à Moncton du 14 au 16 juin 1984, Moncton, Éditions Perce-Neige, 1984, p. 58-59.

+ «Fictions d'ambiance» [avec Claude Beausoleil], Lèvres urbaines, n 6, 1984, p. 3.

+ «16 : naturellement moderne», La Nouvelle Barre du jour, n 141, 1984, p. 94-95.

+ "Choisir la ville», Lèvres urbaines, n 11, 1985, p. 3.

+ «Une avant-garde (au sens populaire)», Atelier de production littéraire des Forges, nos 19-20, 1985, p. 145-146.

+ «Un roman un peu "carré"», La Presse, 29 juillet 2007, p. Arts1.

\section{G. Correspondances et entretien}

+ «Ce n'est pas moi (correspondance)» [avec Charles Guilbert], ETC, n 59, 2002, p. 20-21.

+ «Correspondance Francis Catalano/Michael Delisle» [avec Francis Catalano], Mœbius, n 95 , 2002, p. 79-90.

+ «Commencer à écrire» [avec Lise Tremblay], Zinc. Revue de la relève, n 10, 2007, p. 38-46.

\section{H. Traductions anglaises des œuvres de Michael Delisle}

+ The sailor's disquiet : a novel [Le désarroi du matelot] par Gail Scott, Toronto, Mercury Press, 2000.

+ Helen with a secret and other stories [Helen avec un secret et autres nouvelles] par Gail Scott, Toronto, Mercury Press, 2002. 


\section{R R E C P T I O N C R I T I Q U E}

\section{A. Sur l'auteur et son ouvre en général}

1. Chapitre de livre

+ ROYER, Jean, "La séduction du romanesque», Introduction à la poésie québécoise. Les poètes et les œuvres des origines à nos jours, Montréal, Bibliothèque québécoise, 1989, p. 139-146.

\section{M é moire}

+ HALIN, Francis, La banlieue : de Jacques Ferron à Michael Delisle, mémoire de maîtrise, Montréal, Université McGill, 2008, 89 f.

\section{Articles}

+ BORDELEAU, Francine, "Entre l'urgence de dire et le dur désir de durer», Nuit blanche, n 20, octobre-novembre 1985, p. 46-47.

+ BORDELEAU, Francine, «Les 20 ans de Lèvres urbaines », Lettres québécoises, nº 112, hiver 2003, p. 14.

\section{B. Sur des ouvrages en particulier}

a) L'extase neutre

+ D’ALONSO, Antonio, "L'extase neutre», Nos livres, mars 1985, p. 23-24.

+ LAROSE, Karim, «L'extase neutre et Mélancolie», Aurélien Boivin (dir.), Dictionnaire des œeuvres littéraires du Québec, t. VII : 1981-1985, Montréal, Fides, 2003, p. 351.

+ TOUPIN, Gilles, «Pour simple sujet, les mouvements de l'écriture», La Presse, 23 mars 1985, p. B11.

\section{b) Fontainebleau}

+ [Anonyme], «Prix Émile-Nelligan», Le Soleil, 12 avril 1988, p. B13.

+ BEAUDET, Marie-Andrée, «Fontainebleau », Québec français, n 69, mars 1988, p. 15-16.

+ BROCHU, André, «Langages en liberté», Voix et Images, vol. XIV, nº 1, automne 1988, p. 135-144.

+ BROCHU, André, Tableau du poème, Montréal, XYZ éditeur, coll. «Documents», 1994, p. 218.

+ FORTIN, Marie-Claude, «Voix de faits», Voir, 14 juin 1989, p. 19.

+ LAFLEUR, Annie, «Fontainebleau », Aurélien Boivin (dir.), Dictionnaire des œuvres littéraires du Québec, t. VIII : 1986-1990, Montréal, Fides, 2012, p. 355-356.

+ LAFOREST, Daniel, « Pour un réalisme de la banlieue. Fontainebleau et le passage de Michael Delisle aux Herbes rouges », Luc Bonenfant et Nathalie Watteyne (dir.), Actualités des Herbes rouges, Montréal, Les Herbes rouges, coll. «La vie parallèle», 2013 (à paraître).

+ LAPRÉS, Raymond, «Fontainebleau», Nos livres, avril 1988, p. 19.

+ LARRIVÉE, Isabelle, «Fontainebleau. Cité de mémoire», Voir, 28 janvier 1988, p. 11.

+ NEPVEU, Pierre, «Le petit Farouest de Jacques Ferron », Lectures des lieux, Montréal, Boréal, coll. «Papiers collés», 2004, p. 85-86.

+ NEPVEU, Pierre, «Supplément à l'histoire d'une épidémie», Lectures des lieux, Montréal, Boréal, coll. «Papiers collés», 2004, p. 166-167.

+ ROYER, Jean, «Michael Delisle et Élise Turcotte remportent le prix Émile-Nelligan », Le Devoir, 12 avril 1988, p. 9.

+ TOUPIN, Gilles, «Retrouver Rina Lasnier, l'illuminée», La Presse, 30 avril 1988, p. K4. 


\section{c) Les changeurs de signes}

+ BROCHU, André, «L'interrogation totale de la mort» Voix et Images, vol. XIII, nº 1, automne 1987, p. 165-174.

+ BROCHU, André, Tableau du poème, Montréal, XYZ éditeur, coll. «Documents», 1994, p. 217.

+ GUÉNETTE, Daniel, «Les changeurs de signes », Nos livres, juin 1987, p. 32-33.

+ NEPVEU, Pierre, «L'ère de la sensation vraie», Estuaire, n 46, 1987, p. 83-84.

+ ROYER, Jean, «Le sentiment de la langue», Le Devoir, 28 février 1987, p. C3.

\section{d) Les mémoires artificielles}

+ BROCHU, André, «L'interrogation totale de la mort», Voix et Images, vol. XIII, n 1, automne 1987, p. 165-174.

+ BROCHU, André, Tableau du poème, Montréal, XYZ éditeur, coll. «Documents», 1994, p. 217.

+ LATENDRESSE, Claude, "Les mémoires artificielles», Nos livres, août 1987, p. 15-16.

+ PAQUIN, Jacques, "Les mémoires artificielles [et] Les changeurs de signes », Estuaire, n 46, 1987, p. 83-84.

+ POIRIER, Guy, «Les mémoires artificielles et autres recueils de poésie de Michael Delisle», Aurélien Boivin (dir.), Dictionnaire des œuvres littéraires du Québec, t. VIII : 1986-1990, Montréal, Fides, 2012, p. 544-545.

\section{e) Chose vocale}

+ CORNELLIER, Louis, «La voix altérée», Bernard Pozier (dir.), La poésie au Québec (revue critique) 1990, Trois-Rivières/Joliette, Écrits des Forges/Cégep Joliette-De Lanaudière, 1991, p. 57-58.

+ FORTIN, Marie-Claude, "Voix de faits», Voir, 14 juin 1989, p. 19.

+ GRÉGOIRE, Monique, "Michael Delisle. Chose vocale», Nuit blanche, $n^{\circ} 43$, mars-avril-mai 1991, p. 4.

+ MALENFANT, Paul Chanel, «Dans les chances de la poésie», Voix et Images, vol. XVI, n 1 , automne 1990, p. 176-192.

+ POPOVIC, Pierre, "Chose vocale de Michael Delisle», Spirale, décembre 1991, p. 5.

+ TOUPIN, Gilles, «La tragédie et le bonheur selon Michael Delisle; pour moi, le poème était une façon d'entendre les choses... », La Presse, 4 août 1990, p. I1-I2.

\section{f) Long glissement}

+ CANTIN, David, "Voyages au fond de soi-même», Le Devoir, 21 septembre 1996, p. D4.

+ CORRIVEAU, Hugues, «Long glissement vers l'amour», Lettres québécoises, nº 85, printemps 1997, p. 31-32.

+ PARADIS, Claude, "Long glissement», Nuit blanche, n 67, été 1997, p. 16-17.

+ TOUPIN, Gilles, «Les poètes aussi vieillissent», La Presse, $1^{\text {er }}$ septembre 1996, p. B5.

\section{g) Prière à blanc}

+ CHAREST, Nelson, «L'élan et le décours», Canadian Literature, nº 207, 2010, p. 121-122.

+ CORRIVEAU, Hugues, "Maison à prières», Le Devoir, 17 octobre 2009, p. F4.

+ MALAVOY-RACINE, Tristan, "Prière à blanc», Voir, 8 octobre 2009, en ligne: http://voir.ca/livres/2009/10/01/michael-delisle-priere-a-blanc-2/.

+ SARRAZIN, Sylvain, «Invitation au voyage», Entre les lignes, vol. VI, n 3, 2010, p. 18-19. 


\section{h) Drame privé}

+ BASILE, Jean, «Drame privé: un premier roman qui a du ton!», La Presse, 3 juin 1989, p. K6.

+ BOIVIN, Jean-Roch, "Une œuvre faible en matière grasse et riche en protéines », Le Devoir, 22 juillet 1989, p. C4.

+ CORRIVEAU, Hugues, «La phrase tragique», Trois. Revue d'écriture et d'érudition, vol. V, n 3, 1990, p. 152-153.

+ DUBOIS, Richard, «Kafka Kalmar et Drame privé», Relations, mai 1990, p. 124-125.

+ FORTIN, Marie-Claude, «Post-scriptum», Voir, 18 mai 1989, p. 15.

+ FORTIN, Marie-Claude, «Voix de faits», Voir, 14 juin 1989, p. 19.

+ LAFLEUR, Annie, "Drame privé», Aurélien Boivin (dir.), Dictionnaire des œuvres littéraires du Québec, t. VIII : 1986-1990, Montréal, Fides, 2012, p. 259.

+ MORISSETTE, Rodolphe, "Drame privé: une riche économie de mots", Le Journal de Montréal, 27 mai 1989, p. W19.

+ SALLES, Alain, «Le cœur d'une phrase», Le Monde, 19 octobre 1990, p. 23.

\section{i) Helen avec un secret et autres nouvelles}

+ FITZGERALD, Judith, "Out of Montreal», The Globe and Mail, 15 février 2003, p. D14.

+ GUAY, Hervé, «L'identité précaire», Le Devoir, 11 novembre 1995, p. D17.

+ LANE-MERCIER, Gillian, «De la création à la traduction littéraire», Spirale, n 97, 2004, p. 19-20.

+ LORD, Michel, «Des fragments de vie et leurs secrets», Lettres québécoises, n 82, été 1996, p. 25-26.

+ MARTEL, Réginald, «Michael Delisle: une voix singulière», La Presse, 29 octobre 1995, p. B5.

+ NAREAU, Michel, "Les habitations précaires dans Helen avec un secret de Michael Delisle», René Audet et Philippe Mottet (dir.), Portrait d'une pratique vive. La nouvelle au Québec (19952010), Québec, Nota bene, coll. «Contemporanéités», 2013, p. 45-67.

\section{j) Le désarroi du matelot}

+ BIRON, Michel, "Autour de quelques morts», Voix et Images, vol. XXIV, n 2, hiver 1999, p. 407-412.

+ BROCHU, André, «Tout est possible, mais... », Lettres québécoises, n 95, automne 1999, p. 2021.

+ BROCHU, André, «Le meurtre, point final», Lettres québécoises, n 96, hiver 1999, p. 20-21.

+ CHARTRAND, Robert, "La marche mortelle des vivants», Le Devoir, 17 octobre 1998, p. D3.

+ CHOUINARD, Marie-Andrée, "La chute d'une providence», Le Devoir, 3 octobre 1998, p. D1.

+ HUNT, Nigel, «Misguided Martyrs», The Globe and Mail, 24 février 2001, p. D13.

+ LACHANCE, Lise, «Le désarroi du matelot: court et intense», Le Soleil, 4 octobre 1998, p. B16.

+ LANE-MERCIER, Gillian, «Writing-Translating (from) the In-Between: An Interview with Gail Scott», Studies in Canadian Literature/Études en littérature canadienne, vol. XXXI, n 2, 2006, p. 173-192.

+ MARTEL, Réginald, «Savante déconstruction», La Presse, 20 septembre 1998, p. B4.

\section{k ) Dée}

+ BIRON, Michel, «Il a plu hier», Voix et Images, vol. XXVIII, n³, printemps 2003, p. 145-153.

+ BIRON, Michel, «La rage d'écrire», Le roman québécois, Montréal, Boréal, coll. «Boréal express», 2012, p. 91-95. 
+ CHARTRAND, Robert, «Domaines à occuper», Le Devoir, 5 octobre 2002, p. F5.

+ COLEMAN, Patrick, "Memories of Urban Development: Michael Delisle's Dée», Québec Studies, $\mathrm{n}^{\circ}$ 39, 2005, p. 99-107.

+ DUPUIS, Gilles, «De quelques romans régionaux... », Liberté, vol. LII, n 4, juin 2011, p. 28-31.

+ GIGUÈRE, Suzanne, «Le bonheur confisqué», La Presse, 29 septembre 2002, p. F2.

+ JARRY, Johanne, «Dée», Nuit blanche, n 89, hiver 2002-2003, p. 10-11.

+ MARCOTTE, Gilles, "Sexe, amour et catastrophes», L'actualité, vol. XXVII, nº 18, 2002, p. 137.

+ MAVRIKAKIS, Catherine, "Dée de Michael Delisle », Gilles Dupuis et Klaus-Dieter Ertler (dir.), À la carte. Le roman québécois (2000-2005), Francfort, Peter Lang, 2007, p. 123-136.

+ MONTPETIT, Caroline, «Mort en banlieue», Le Devoir, 14 septembre 2002, p. D1.

+ MOTTET, Philippe, «La banlieue romanesque entre nature et culture», Etudes canadiennes/Canadian Studies. Revue interdisciplinaire des études canadiennes en France, nº 60, 2006, p. 65-74.

+ NAREAU, Michel, «Dée», Nuit blanche, no 109, été 2007, p. 24.

+ NAREAU, Michel, «Lisières du monde et recyclage des mémoires dans Dée de Michael Delisle», British Journal of Canadian Studies, vol. XXIV, nº 2, 2011, p. 177-193.

+ NAVARRO, Pascale, "Terre des hommes», Voir, 12 septembre 2002, p. 36-37.

+ PAQUIN, Éric, «Dée», Voir, 3 mai 2007, p. 47.

+ POULiN, Marie-Michèle, «Dée», Québec français, no 129, printemps 2003, p. 18-19.

+ RIOUX, Hélène, «Petites et grandes misères », Lettres québécoises, n 109, printemps 2003, p. 27-28.

\section{1) Le sort de Fille}

+ BIRON, Michel, «Familles, je vous... », Voix et Images, vol. XXXI, n 2, hiver 2006, p. 153-158.

+ CUSSON, Marie, "Rencontres urbaines et mouvances identitaires dans "Le pont" de Michael Delisle et “Je n'ai pas porté plainte" de Robert Lalonde», Québec Studies, n 40, 2005, p. 3-18.

+ DEITZ, Ritt, «Montréal, la marge au cœur», The French Review, vol. LXXX, nº 1, 2006, p. 234235.

+ FOGLIA, Pierre, «Lisez au moins...», La Presse, 9 janvier 2007, p. A5.

+ GIGUÈRE, Suzanne, «Michael Delisle et la cartographie de la marge», Le Devoir, 8 octobre 2005, p. F3.

+ JUTRAS, Benoît, «Michael Delisle. L'invention de la solitude», Voir, 6 octobre 2005, p. 55.

+ LORD, Michel, «Une singulière relation», Lettres québécoises, n 121, printemps 2006, p. 35.

+ MARCOTTE, Gilles, «Faut-il tuer papa ? ", L'actualité, vol. XXXI, nº 1, 2006, p. 63

+ MARTEL, Réginald, «Des nouvelles d'un réalisme sans ornements», La Presse, 30 octobre 2005, p. Arts16.

+ NAREAU, Michel, «Le sort de Fille», Nuit blanche, no 103, été 2006, p. 18-19.

+ TORCHI, Francesca, «L'adolescent périphérique. Montréal dans les nouvelles "Le pont” de Michael Delisle et "Piercing" de Larry Tremblay ", Études canadiennes/Canadian Studies. Revue interdisciplinaire des études canadiennes en France, nº 64, 2008, p. 175-186.

+ TREMBLAY, Nicolas, "Saleté et épiphanie», XYZ. La revue de la nouvelle, nº 93, printemps 2008, p. 85-92.

\section{m) Tiroir no 24}

+ CORRIVEAU, Hugues, «Boulanger dérangé», Lettres québécoises, no 141, printemps 2011, p. 19. 
+ DENIS-MELANÇON, Maude, "Mal aimé», Le Nouvelliste, 26 février 2011, p. E8.

+ DESMEULES, Christian, «Visites à domicile», Le Devoir, 2 avril 2011, p. F3.

+ GUY, Chantal, «Tiroir n 24 : né pour un petit pain», La Presse, 17 septembre 2010, p. Arts4.

+ LAURIN, Danielle, "Né pour un p'tit pain», Le Devoir, 4 décembre 2010, p. F3.

+ NAREAU, Michel, «Tiroir no 24 », Nuit blanche, nº 121, hiver 2011, p. 29-30.

+ PAQUIN, Éric, «Tiroir n 24 », Voir, 14 octobre 2010, en ligne: http://voir.ca/livres/2010/10/14/michael-delisle-tiroir-n \% C2 \% B0-24/.

+ VILLENEUVE, Kathryn, «Un tiroir rempli de promesses», Le Devoir, 7 mai 2011, p. F2.

+ VILLENEUVE-CÔTÉ, Francis, «Dérive identitaire», Le Nouvelliste, 26 février 2011, p. E8. 